\title{
Sol-Gel Synthesis of Nanoparticles of $N, S$-Codoped Titanium Dioxide and its Use for Photocatalytic Degradation of Trypan Blue
}

\author{
AJAY SINGH SISODIYA ${ }^{1}$, DIPTI SONI ${ }^{1}$, RAKSHIT AMETA ${ }^{1}$ and K. L. AMETA ${ }^{*}, 2$ \\ ${ }^{1}$ Department of Chemistry, PAHER University, Udaipur - 313003 (Raj), India \\ ${ }^{2}$ Department of Chemistry, Mody University of Science and Technology, \\ Lakshmangarh - 332311 (Raj), India \\ klameta77@hotmail.com
}

Received 9 February 2015 / Accepted 13 February 2015

\begin{abstract}
In recent years, heterogeneous photocatalysis has gained wide attention in water purification as one of the important advanced oxidation processes (AOPs) due to its effectiveness in degrading and mineralizing the organic compounds. N, S-codoped $\mathrm{TiO}_{2}$ has been prepared by solgel method with thiourea as dopant source. The rate of photocatalytic degradation of dye was monitored spectrophotometrically. The effect of variation of different parameters like $\mathrm{pH}$, concentration trypan blue, amount of photocatalyst, dopant percentage and light intensity on the rate of photocatalytic degradation of dye was observed. A tentative mechanism for the photocatalytic degradation of trypan blue has also been proposed.
\end{abstract}

Keywords: Photocatalytic degradation, $N$, S-codoped titanium dioxide, Trypan blue

\section{Introduction}

Contamination of water and air due to organic matter poses severe threat to life on the earth ${ }^{1}$. Dyes are widely used in many industries such as textile, leather tanning, food industry etc. It was reported that the amount of current world's dyestuffs production is about 10 million $\mathrm{Kg}$ per year and between 1 to 2 million $\mathrm{kg}$ of active dyes have entered the biosphere, either in dissolved or suspended form in water ${ }^{2}$. Advanced oxidation process (AOP) is emerging as a promising technology, which has been successfully used to decompose many hazardous chemical compounds to acceptable levels, without producing sludge, which requires further handling ${ }^{3}$. There are various methods for removal of organic and inorganic compounds from the wastewater as filtration, electrolysis, precipitation, ion exchange and adsorption process ${ }^{4}$. Most of these methods require high capital and recurring expenditure and consequently, they are not suitable for small scale industries ${ }^{5}$.

Among all these methods, photocatalysis is highly effective and low cost process than the other methods. $\mathrm{TiO}_{2}$ is an important photocatlayst, because it is more efficient and shows 
the highest quantum yield ${ }^{6}$. The necessary wavelength for $\mathrm{TiO}_{2}$ excitation is about $380 \mathrm{~nm}$, and therefore, ultraviolet light is required to activate it. $\mathrm{TiO}_{2}$ Degussa P25 can function in presence of the sunlight due to the UV light, it is only 5\% of solar energy reaching the Earth. One of the methods to improve photocatalytic activity of $\mathrm{TiO}_{2}$ is to dope it with non-metal or metal impurity or to couple it with lower band gap semiconductor ${ }^{7}$. The role of transition metal ion in $\mathrm{TiO}_{2}$ is that these ions offer a way to trap the charge carrier; thus, improving the efficiency of catalyst. Noble metal doped or deposited on $\mathrm{TiO}_{2}$ shows enhanced photocatalytic activity of $\mathrm{TiO}_{2}{ }^{8}$. Among the noble metals, silver ions have attracted interests of several researchers, because of its novel effects on the improvement of photoactivity of semiconductor photocatalysis ${ }^{9}$. $\mathrm{TiO}_{2}$ can be doped with silver using photodeposition process $^{10}$, chemical reduction of silver ion on $\mathrm{TiO}_{2}$ nanoparticles ${ }^{11}$, thermal deposition ${ }^{12}$ and pulsed laser deposition ${ }^{13}$. The most feasible method for improving the photocatalytic performance of titania is doping with metals as well as non-metals. Sato reported $\mathrm{N}$-doped titania by annealing the mixture of a commercial titanium hydroxide and $\mathrm{NH}_{4} \mathrm{Cl}$ or $\mathrm{NH}_{4} \mathrm{OH}$, which showed higher photocatalytic activity in the visible light region ${ }^{14}$.

\section{Materials and methods}

The dye trypan blue (TB) was obtained from sd-fine Chem and was used as such without purification $\left(\lambda_{\max }=610 \mathrm{~nm}\right)$. Other chemicals materials such as $\mathrm{Ti}(\mathrm{OiPr})_{4}$ and thiourea were purchased from Spectrochem and Himedia, respectively. The dye solutions were prepared using doubly distilled water as and when required. A $200 \mathrm{~W}$ tungsten lamp (Phillips) was used for irradiating the solution in the visible range. UV-Visible spectrophotometer (Systronics Model 106) was used for measuring optical density at different time intervals. The $\mathrm{pH}$ of the solution was adjusted with previously standardized $\mathrm{H}_{2} \mathrm{SO}_{4}$ and $\mathrm{NaOH}$ solutions.

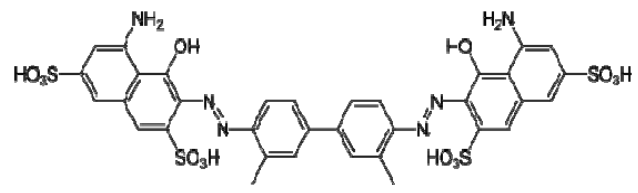

Structure of Trypan blue

\section{Experimental}

A mixture of $10 \mathrm{~mL}$ of $\mathrm{Ti}(\mathrm{OiPr})_{4}, 50 \mathrm{~mL}$ of isopropyl alcohol and $100 \mathrm{~mL}$ of doubly distilled water was vigorously stirred and the solution was stand overnight at room temperature. Then the solution was dried in oven at $80^{\circ} \mathrm{C}$ for 2 hours and calcined at $400{ }^{\circ} \mathrm{C}$ for 3 hours in furnace. Pure $\mathrm{TiO}_{2}$ was obtained in the form of white powder.

\section{Preparation of $\mathrm{N}$, S-codoped $\mathrm{TiO}_{2}$}

A mixture of $10 \mathrm{~mL}$ of $\mathrm{Ti}(\mathrm{OiPr})_{4}, 50 \mathrm{~mL}$ of isopropyl alcohol and $0.5,1,1.5,2.0$ or $2.5 \mathrm{~g}$ of thiourea in $100 \mathrm{~mL}$ of doubly distilled water was taken in five different beakers, respectively. The solution was vigorously stirred and was stand overnight at room temperature. Then each solution was dried in an oven at $80{ }^{\circ} \mathrm{C}$ for 2 hours and calcined at $400{ }^{\circ} \mathrm{C}$ for 3 hours to get $N, S$ - codoped $\mathrm{TiO}_{2}$, which was pale yellow in color. Different $N$, S-codoped titania powders were obtained with different amount of dopant source i.e. 0.5, $1.0,1.5,2.0$ and $2.5 \%$, respectively.

A stock solution of trypan blue $\left(1.0 \times 10^{-3} \mathrm{M}\right)$ was prepared in doubly distilled water. This stock solution was further diluted as and when required. The absorbance of this solution 
was determined with the help of UV-Visible spectrophotometer (Systronics Model 106) at $\lambda_{\max }=610 \mathrm{~nm}$. The solution of trypan blue $3.60 \times 10^{-5} \mathrm{M}$ was prepared in doubly distilled water and $0.12 \mathrm{~g}$ of $\mathrm{N}, \mathrm{S}$-doped $\mathrm{TiO}_{2}$ was added to it. The $\mathrm{pH}$ of reaction mixture was maintained at 7.5 and this solution was exposed to a $200 \mathrm{~W}$ tungsten lamp. A decrease in absorbance of trypan blue solution was observed with increasing time of exposure. Rate constant was calculated by the equation: $\mathrm{k}=2.303 \times$ slope. The typical runs for the photocatalytic degradation of trypan blue in the presence of pure $\mathrm{TiO}_{2}$ and $\mathrm{N}$, S-doped $\mathrm{TiO}_{2}$ have been presented in Table 1 and graphically represented in Figure 1.

Table 1. A typical run for the photocatalytic degradation of trypan blue

\begin{tabular}{ccccc}
\multicolumn{2}{c}{$\begin{array}{c}\text { pH }=7.5 \\
N, S \text {-codoped } \mathrm{TiO}_{2}=0.12 \mathrm{~g}(2.0 \%)\end{array}$} & \multicolumn{2}{c}{$\begin{array}{c}\text { [Trypan blue] }=3.60 \times 10^{-5} \mathrm{M} \\
\text { Light Intensity }=50.0 \mathrm{mWcm}^{-2}\end{array}$} \\
\hline \multicolumn{3}{c}{ Pure $\mathrm{TiO}_{2}$} & \multicolumn{3}{c}{ N, S-codoped $\mathrm{TiO}_{2}$} \\
\hline Time, min. & $\begin{array}{c}\text { Optical Density } \\
\text { (O. D.) }\end{array}$ & $1+\log$ O. D. & $\begin{array}{c}\text { Optical Density } \\
\text { (O. D.) }\end{array}$ & $1+\log$ O. D. \\
\hline 0 & 0.842 & 0.925 & 0.842 & 0.925 \\
10 & 0.832 & 0.920 & 0.825 & 0.916 \\
20 & 0.814 & 0.910 & 0.805 & 0.905 \\
30 & 0.792 & 0.989 & 0.782 & 0.893 \\
40 & 0.780 & 0.891 & 0.765 & 0.883 \\
50 & 0.762 & 0.881 & 0.723 & 0.859 \\
60 & 0.745 & 0.872 & 0.702 & 0.846 \\
70 & 0.724 & 0.859 & 0.682 & 0.833 \\
80 & 0.692 & 0.840 & 0.664 & 0.822 \\
90 & 0.674 & 0.828 & 0.648 & 0.811 \\
\hline
\end{tabular}

Rate constant for $\mathrm{N}$, S-codoped $\mathrm{TiO}_{2} ; k=5.03 \times 10^{-5} \mathrm{~s}^{-1}$, Rate constant for pure $\mathrm{TiO}_{2} ; k=3.43 \times 10^{-5} \mathrm{~s}^{-1}$

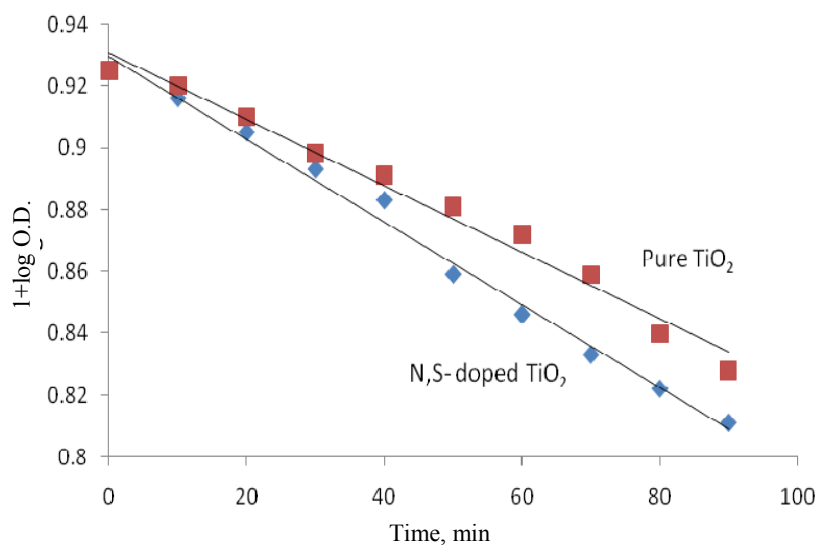

Figure 1. A typical run

Different rate affecting parameters influence the photocatalytic degradation of the dye and therefore, these were varied to find out the optimum conditions for the degradation of the dye.

\section{Effect of $\mathrm{pH}$}

The $\mathrm{pH}$ of the solution is likely to affect the degradation rate of the trypan blue. The effect of $\mathrm{pH}$ on the rate of degradation of the dye was investigated in the $\mathrm{pH}$ range $5.0-9.5$. The results are reported in Table 2 . 
Table 2. Effect of $\mathrm{pH}$

\begin{tabular}{cc}
$\begin{array}{c}\text { [Trypan blue] }=3.60 \times 10^{-5} \mathrm{M} \\
\text { Light Intensity }=50.0 \mathrm{mWcm}^{-2}\end{array}$ & $\begin{array}{c}\mathrm{N}, \mathrm{S}-\text { codoped } \mathrm{TiO}_{2}=0.12 \mathrm{~g} \\
\text { o of dopant }=2.0\end{array}$ \\
\hline $\mathrm{pH}$ & $\mathrm{k} \times 10^{5}, \mathrm{sec}^{-1}$ \\
5.0 & 3.42 \\
5.5 & 3.85 \\
6.0 & 4.17 \\
7.5 & 4.40 \\
7.5 & 4.58 \\
8.0 & 5.03 \\
8.5 & 4.85 \\
9.0 & 4.56 \\
9.5 & 4.33 \\
\hline
\end{tabular}

It has been observed that the rate of photocatalytic degradation of trypan blue was increased as $\mathrm{pH}$ was increased from 5.0 to 7.5 and it got an optimum value at $\mathrm{pH}$ 7.5. On further increasing the $\mathrm{pH}$, the rate of the reaction was decreased. This behavior may be explained on the basis that the rate of photocatalytic degradation of dye increases when $\mathrm{pH}$ was increased from 5.0 to 7.5 as the availability of reducing species $\mathrm{O}_{2}^{-\bullet}$ will increase. Thus, the rate of photocatalytic degradation of the dye increases. Above $\mathrm{pH} 7.5$, a decrease in the rate of photocatalytic degradation of the dye was observed, which may be due to the fact that cationic form of trypan blue converts in its neutral form, which faces no attraction towards the negatively charged semiconductor surface and $\mathrm{O}_{2}{ }^{-}$. Hence, the rate is retarded.

\section{Effect of trypan blue concentration}

The effect of dye concentration was also observed by taking different concentrations of the dye. The results are tabulated in Table 3 .

Table 3. Effect of trypan blue concentration

\begin{tabular}{cc}
$\begin{array}{c}\mathrm{pH}=7.5 \\
\text { Light Intensity }=50.0 \mathrm{mWcm}^{-2}\end{array}$ & $\begin{array}{r}N, S \text {-codoped } \mathrm{TiO}_{2}=0.12 \mathrm{~g} \\
\% \text { of dopant }=2.0\end{array}$ \\
\hline [Trypan blue] $\times 10^{5} \mathrm{M}$ & $\mathrm{k} \times 10^{5} \mathrm{sec}^{-1}$ \\
\hline 3.00 & 3.73 \\
3.10 & 3.99 \\
3.20 & 4.14 \\
3.30 & 4.37 \\
3.40 & 4.61 \\
3.50 & 4.81 \\
3.60 & 5.03 \\
3.70 & 4.71 \\
3.80 & 4.41 \\
3.90 & 4.14 \\
\hline
\end{tabular}

It is evident from the data that the rate of photocatalytic degradation of dye increases with an increase in concentration of the dye. It may be explained on the basis that as the concentration of the dye was increased, more dye molecules were available for excitation and consecutive energy transfer and hence, an increase in the rate of photocatalytic degradation of the dye was observed. The rate of photocatalytic degradation was found to 
decrease with an increase in the concentration of dye above $3.60 \times 10^{-5} \mathrm{M}$. It may be due to the fact that the dye itself may start acting as an internal filter for the incident light and it will not permit the desired light intensity to reach the semiconductor particles and as a result, the degradation rate decreases.

\section{Effect of amount of $\mathrm{N}$, S-codoped $\mathrm{TiO}_{2}$}

The effect of amount of semiconductor was observed by taking different amount of semiconductor. The results are reported in Table 4.

Table 4. Effect of amount of $N$, S-codoped $\mathrm{TiO}_{2}$

\begin{tabular}{|c|c|}
\hline $\begin{array}{l}\mathrm{pH}=7.5 \\
\text { Light Intensity }=50.0 \mathrm{~mW} \mathrm{~cm}^{-2}\end{array}$ & $\begin{array}{r}\text { Trypan blue }]=3.60 \times 10^{-5} \mathrm{M} \\
\% \text { of dopant }=2.0\end{array}$ \\
\hline Amount of $\mathrm{N}, \mathrm{S}$-codoped $\mathrm{TiO}_{2}, \mathrm{~g}$ & $\mathrm{k} \times 10^{5}, \mathrm{sec}^{-1}$ \\
\hline 0.02 & 4.03 \\
\hline 0.04 & 4.23 \\
\hline 0.06 & 4.47 \\
\hline 0.08 & 4.63 \\
\hline 0.10 & 4.81 \\
\hline 0.12 & 5.03 \\
\hline 0.14 & 4.96 \\
\hline 0.16 & 4.92 \\
\hline
\end{tabular}

It was observed that the rate of reaction was increased with increase in the amount of semiconductor $N, S$-codoped $\mathrm{TiO}_{2}$. The rate of degradation was optimum at $0.12 \mathrm{~g}$ of the photocatalyst. Beyond $0.12 \mathrm{~g}$, the rates of reaction become virtually constant. This may be due to fact that as the amount of semiconductor was increased, the exposed surface area of the semiconductor also increases. However, after this limiting value $(0.12 \mathrm{~g})$, an increase in the amount of semiconductor only increases the thickness of the semiconductor layer and not the exposed surface area. This was also confirmed by using reaction vessels of different dimensions. It was observed that the point of saturation is shifted to a higher value for vessels of larger capacities while it is shifted to lower value for vessels of smaller capacities.

\section{Effect of \% variation of dopant}

The effect of $\%$ variation of dopant was observed by taking different $\%$ of dopant i.e. thiourea. The results are reported in Table 5.

Table 5. Effect of \% variation of dopant

\begin{tabular}{|c|c|}
\hline $\begin{array}{c}\mathrm{pH}=7.5 \mathrm{~N}, S \text {-codoped } \\
\text { Light Intensity }=50.0 \mathrm{~mW}\end{array}$ & $\begin{aligned} \mathrm{TiO}_{2} & =0.12 \mathrm{~g} \\
{[\text { Trypan blue }] } & =3.60 \times 10^{-5} \mathrm{M}\end{aligned}$ \\
\hline Dopant, \% & $\mathrm{k} \times 10^{5}, \mathrm{sec}^{-1}$ \\
\hline 0.5 & 4.44 \\
\hline 1.0 & 4.61 \\
\hline 1.5 & 4.89 \\
\hline 2.0 & 5.03 \\
\hline 2.5 & 4.83 \\
\hline
\end{tabular}

It was observed that as the $\%$ of dopant source was increased, the rate constant was also increased. At $2.0 \%$ of dopant, the rate of reaction was optimum and after that, rate of reaction was decreased. It may be due to the reason that freely active site of titania decreases after this dopant concentration and therefore, the rate of reaction started decreasing. 


\section{Effect of light intensity}

To investigate the effect of light intensity on the photocatalytic degradation of trypan blue, the distance between the light source and the exposed surface area was varied. The results are summarized in Table 6 .

Table 6. Effect of light intensity

\begin{tabular}{cc}
$\mathrm{pH}=7.5$ & $\begin{array}{c}\text { Trypan blue }=3.60 \times 10^{-5} \mathrm{M} \\
\% \text { of dopant }=2.0\end{array}$ \\
$N$, S-codoped $\mathrm{TiO}_{2}=0.12 \mathrm{~g}$ & $\mathrm{k} \times 10^{5}, \mathrm{sec}^{-1}$ \\
\hline Intensity of light, $\left.\mathrm{mWcm}^{-2}\right)$ & 4.13 \\
20.0 & 4.37 \\
30.0 & 4.53 \\
40.0 & 5.03 \\
50.0 & 4.83 \\
60.0 & 4.68 \\
70.0 &
\end{tabular}

The results indicate that photocatalytic degradation of a trypan blue was accelerated as the intensity of light was increased from 20.0 to $50.0 \mathrm{~mW} \mathrm{~cm}$, because an increase in the light intensity will increase the number of photons striking per unit area of semiconductor surface per unit time. On further increasing the intensity of light above $50.0 \mathrm{~mW} \mathrm{~cm}$, there was a decrease in the rate of reaction. This may be due to some side reactions or thermal effect.

\section{Mechanism}

On the basis of these observations, a tentative mechanism for photocatalytic degradation of trypan blue may be proposed as -

$$
\begin{aligned}
& { }^{1} \mathrm{~TB}_{0} \stackrel{{ }^{h v}}{\longrightarrow}{ }^{1} \mathrm{~TB}_{1} \\
& { }^{1} \mathrm{~TB}_{1} \stackrel{\mathrm{ISC}}{\longrightarrow}{ }^{3} \mathrm{~TB}_{1} \\
& \mathrm{SC} \stackrel{\mathrm{hv}}{\longrightarrow} \mathrm{e}^{-}(\mathrm{CB})+\mathrm{h}^{+}(\mathrm{VB}) \\
& e^{-}+\mathrm{O}_{2} \longrightarrow \mathrm{O}_{2}^{-\cdot} \\
& \mathrm{O}_{2}^{-\bullet}+{ }^{3} \mathrm{~TB}_{1} \longrightarrow \text { Leuco TB } \\
& \text { Leuco } \mathrm{TB} \longrightarrow \text { Products }
\end{aligned}
$$

Trypan blue (TB) absorbs radiations of suitable wavelength and gives rise to its excited singlet state. Then it undergoes intersystem crossing (ISC) to give the triplet state of the dye. On the other hand, the semiconducting $\mathrm{TiO}_{2}$ (SC); (doped or undoped) also utilizes the radiant energy to excite its electron from valence band to the conduction band. This electron will be abstracted by oxygen molecule (dissolved oxygen) generating superoxide anion radical $\left(\mathrm{O}_{2}^{-\bullet}\right)$. This anion radical will reduce the dye trypan blue to its leuco form, which may ultimately degrade to products. It was also confirmed that this degradation proceeds through reduction and not oxidation. ${ }^{\circ} \mathrm{OH}$ radical does not participate as an active oxidizing species as confirmed by using hydroxyl radical scavenger (2-propanol), where the rate of degradation was not affected appreciably.

\section{Conclusion}

Doping of titania with non-metal reduces its band gap and accordingly its activity is increased. In the present work, it was confirmed by using pure $\mathrm{TiO}_{2}$ and $N$, S-codoped $\mathrm{TiO}_{2}$ semiconductor for photocatalytic degradation of trypan blue dye. The results showed higher 
rate constant for $N$, S-codoped $\mathrm{TiO}_{2}$ than pure $\mathrm{TiO}_{2}$, which revealed that doped $\mathrm{TiO}_{2}$ extended the absorption of $\mathrm{TiO}_{2}$ into the visible light range.

\section{References}

1. Matthews R W, Water Res., 1991, 25(10), 1169-1176; DOI:10.1016/00431354(91)90054-T

2. Allen S J, Gan Q, Matthews R and Johnson P A, Bioresour Technol., 2003, 88(2), 143-152; DOI:10.1016/S0960-8524(02)00281-X

3. Han F, Kambala V S R, Srinivasan M, Rajarathnam D and Naidu R, Appl Catal A: Gen., 2009, 359(1-2), 25-40; DOI:10.1016/j.apcata.2009.02.043

4. Lee K, Lee N H, Shin S H, Lee H G and Kima S J, Mat Sci Eng B, 2006, 129(1-3), 109-115; DOI:10.1016/j.mseb.2005.12.032

5. Chenthamarakshan C R, Rajeshwar K and Wolfrum E J, Langmuir, 2000, 16(6), 2715-2721; DOI:10.1021/la9911483

6. Michael R H, Scot T M, Woneyong C and Detlef W B, Chem Rev., 1995, 95(1), 69-96; DOI:10.1021/cr00033a004

7. Chen X and Mao S S, Chem Rev., 2007, 107(7), 2891-2959; DOI:10.1021/cr0500535

8. Zhu J, Yang D, Geng J, Chen D and Jiang Z, J Nanoparticle Res., 2008, 10(5), 729736; DOI:10.1007/s11051-007-9301-z

9. Sobana N, Murugandham M and Swaminathan M, J Mol Catal A: Chem., 2006, 258, 124-132; DOI:10.1016/j.molcata.2006.05.013

10. Tayade R J, Kulkarni R G and Jasra R V, Industrial Eng Chem Res., 2006, 45(15), 5231-5238; DOI:10.1021/ie051362o

11. Whang T J, Huang H Y, Hseih M T and Chen J J, Int J Mol Sci., 2009, 10, $4707-$ 4718; DOI:10.3390/ijms10114707

12. Seery M K, George R M, Horis P and Pillai S P, J Photochem Photobiol A: Chem., 2007, 189(2-3), 258-263; DOI:10.1016/j.jphotochem.2007.02.010

13. Wang H W, Lin H C, Kuo C H, Cheng Y L and Yeh Y C, J Phys Chem Solids, 2008, 69(2-3), 633-636; DOI:10.1016/j.jpcs.2007.07.052

14. Asahi R, Morikawa T, Ohwaki T, Aoki K and Taga Y, Science, 2001, 293(5528), 269-271. 